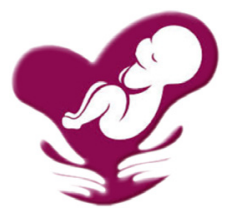

Published by DiscoverSys

\section{Rhesus incompatibility in pregnancy: a case report}

\author{
Ali Sungkar ${ }^{1 *}$, Raymond Surya ${ }^{1}$, Andrew Pratama Kurniawan ${ }^{2}$
}

'Department of Obstetrics and Gynecology, Faculty of Medicine, Universitas Indonesia/Dr. Cipto Mangunkusumo Hospital, Jakarta, Indonesia

${ }^{2}$ Faculty of Medicine, Universitas Indonesia, Jakarta, Indonesia

*Corresponding to: Ali Sungkar; Department of Obstetrics and Gynecology, Faculty of Medicine, Universitas Indonesia/ Dr. Cipto Mangunkusumo Hospital, Jakarta, Indonesia.

alisungkar@yahoo.com
Received: 2020-06-27 Accepted: 2020-07-31 Published: 2020-08-26

\section{INTRODUCTION}

Hemolytic disease of the fetus and newborn (HDFN) occurs due to the destruction of red blood cells, usually following a rhesus incompatibility. ${ }^{1}$ Rh-negative mothers carrying an Rh-positive fetus may produce antibodies against $\mathrm{D}$-antigen (anti-D) following maternal exposure to fetal blood that usually occurs at birth. This event is known as sensitization. It occurs even after a small amount of fetal red blood cells in maternal circulation. Following sensitization, it requires between five to fifteen weeks for the corresponding antibodies to appear in maternal circulation. Most of the time, it does not give any harm to the first baby because the pregnancy is generally completed by the time that sensitization occurred. However, these maternal antibodies may cause hemolytic disease in subsequent pregnancies with Rh-positive fetus. ${ }^{2}$ Prenatal consequences may vary from no effect to hydrops fetalis or intrauterine fetal death depending on the type of antibody, quantity, and affinity for the corresponding antigen. ${ }^{3}$

Although, anti-D $\operatorname{IgG}$ has been approved for routine antepartum prophylaxis since $1976 .{ }^{4}$ Maternal alloimmunization still occurs around 0.4 per 1,000 births or approximately $1 \%$ to $2 \%$ of serologically D-negative women in Canada and United Kingdom due to failure of administering anti-D immune globulin or inadequate dosing schedules. ${ }^{5,6}$ For more than 30 years, the most frequent immunization is against $\mathrm{RhD}(\mathrm{RH} 1)$, with 6 cases per 1,000 live births in the USA and approximately 750 cases per year in France. ${ }^{3}$ This alloimmunization is the leading cause of fetal anemia.

This study aims to present a case of rhesus incompatibility in pregnancy without any effect on the baby.

\section{CASE}

A-38-years-old Indonesian woman with gravida 4 para 3 (G4P3), 32 weeks of gestational age, came to the emergency department due to vaginal bleeding. Her history of previous pregnancies was unremarkable. All children were born spontaneously at term without any complication, as well as they grew and developed normally. The physical and obstetrical examination was within normal limits corresponding to her gestational age. Laboratory examination revealed an anemic state (hemoglobin level $7.1 \mathrm{~g} / \mathrm{dL}$ ) and was planned for blood transfusion. On blood typing, she had an 
A-negative (A-) blood type. We also checked her husband, and he had an O-positive $(\mathrm{O}+)$ blood type. All children were also examined for the blood type, and the results were all $\mathrm{O}$-positive $(\mathrm{O}+)$ (Table 1). From the ultrasound examination, the middle cerebral artery peak systolic velocity (PSV) was 22 $\mathrm{cm} /$ second corresponding to 0.49 multiples of the median (MoM).

The patient eventually underwent a cesarean section due to recurrent antepartum hemorrhage due to the total placenta previa. The cesarean section continued with tubectomy Pomeroy. Gave birth to a female baby, weighed 2,220 grams with an A-positive blood type. The hemoglobin level was $14.6 \mathrm{~g} / \mathrm{dL}$ without any sign of neonatal jaundice/ icterus during the first 24 hours of life. The baby was discharged without any complications.

\section{DISCUSSION}

During pregnancy, a volume of fetal red blood cells escapes into the maternal intervillous space. This phenomenon can trigger maternal red cell isoimmunization. ${ }^{7,8}$ During the first exposure, the primary maternal antibody produces IgM isotype, and the response is usually mild and even asymptomatic. However, second exposure will trigger IgG production, destroying fetal red blood cells through the transplacental passage. ${ }^{9}$ This phenomenon is called hemolytic disease of the fetus and newborn or erythroblastosis fetalis. The consequences are anemia of the newborn, hydrops or intrauterine death for severe cases. ${ }^{7-9}$

The International Society of Blood Transfusion

Table 1. Laboratory Results

\begin{tabular}{ccc}
\hline Patient's Data & Result & Reference Value \\
\hline Hemoglobin & $7.1 \mathrm{~g} / \mathrm{dL}$ & $12.0-14.0$ \\
Hematocrit & $20.5 \%$ & $37.0-43.0$ \\
Erythrocyte & $2.52 \times 10^{6} \mu \mathrm{L}$ & $4.0-5.0$ \\
MCV & $81.3 \mathrm{fl}$ & $82.0-92.0$ \\
MCH & $28.2 \mathrm{pg}$ & $27.0-31.0$ \\
MCHC & $34.6 \mathrm{~g} / \mathrm{dl}$ & $32.0-36.0$ \\
Leukocyte & $13.82 \times 10^{3} \mu \mathrm{L}$ & $5.0-10.0$ \\
Thrombocyte & $181 \times 10^{3} \mu \mathrm{L}$ & $150-400$ \\
Blood Type & A-negative & \\
The Husband & & \\
Blood Type & O-positive & \\
First Child & & \\
Blood Type & O-positive & \\
Second Child & & \\
Blood Type & O-positive & \\
Third Child & & \\
Blood Type & O-positive & \\
\hline
\end{tabular}

(ISBT) had recognized 360 groups of antigens in 36 blood group systems. Only some antigens in those groups are clinically and immunologically important, one among those is $\mathrm{CDE}$ (rhesus) blood group or $\mathrm{RhD}$ antigen. ${ }^{7,10} \mathrm{In} \mathrm{RhD}$ alloimmunization, when an RhD-negative pregnant woman exposed to $\mathrm{RhD}$-positive fetus, she is at risk of developing anti-D antibodies. ${ }^{7,8}$ As the gestational age advancing, spontaneous fetomaternal hemorrhages could occur with increasing frequency and volume. In the majority of cases, the antigenic load of $\mathrm{RhD}$ antigen on fetal erythrocytes and erythrocytic precursors was insufficient to stimulate the maternal immune system. In cases of antenatal or at delivery with fetomaternal hemorrhage, the maternal $\mathrm{B}$ lymphocyte that recognizes the $\mathrm{RhD}$ antigen initiates the immune response. The initial maternal response is the production of immunoglobulin $\mathrm{M}$ (IgM) anti-D that is short-lived, then followed with a rapid change to an immunoglobulin $G$ (IgG) response. The immunological response also produces memory B-lymphocytes that await a new antigenic exposure in a subsequent pregnancy. When it encounters the rhesus antigen, it will sensitize and produces IgG antibodies and increase maternal titer rapidly. Moreover, maternal IgG could cross the placental barrier and destroy any $\mathrm{RhD}$-positive erythrocytes, thus resulting in fetal anemia. $^{3}$

In our case, the mother had been exposed three times of $\mathrm{RhD}$-positive fetus in which probably none of them triggered the $\mathrm{RhD}$ alloimmunization. Several theories could explain this phenomenon. First, the low incidence of $\mathrm{RhD}$ alloimmunization is due to antenatal immune prophylaxis program that has been initiated since $1976 .{ }^{4}$ However, she did not have any history of immune-prophylaxis. Second, the rhesus blood group consisted of five antigens, namely C, c, D, E, and e (rhesus-positive) and no antigens (rhesus-negative). The $\mathrm{C}, \mathrm{c}, \mathrm{E}$, and e antigens have lower immunogenicity than the D-antigen. ${ }^{7}$ In our hypothesis, all children had low immunogenicity, thus resulted in a non-significant immune reaction observed in this pregnancy, however. Although it needs further testing through polymerase chain reaction (PCR) to determine the genetic component of the rhesus blood group. Third, the alloimmunization response is dose-dependent to fetal blood volume. The immune response occurs in $15 \%$ after exposure of $1 \mathrm{~mL}$ of Rh-positive cells, while $70 \%$ after $250 \mathrm{~mL}^{8}{ }^{8}$ In the meantime, several events will likely increase the volume of fetal blood exposed to maternal circulation and subsequently increase the risk of immune sensitization. Those events include early pregnancy loss (miscarriage, missed abortion, ectopic pregnancy), procedures 
prone to the risk of fetomaternal hemorrhages such as chorionic villus sampling, amniocentesis, fetal blood sampling, maternal trauma, manual placental removal, and external version. Fourth, ABOincompatibility between mother and fetus will rapidly clear the red blood cells before triggering maternal immune response. ${ }^{3}$ In our case, all children do not have $\mathrm{ABO}$ incompatibilities. Lastly, it is related to the maternal genetic component that influences immune response (HLA differences, TRIM 21 (RO52) and CD81 polymorphism) and immune status (immunodeficiency and chronic autoimmune diseases). ${ }^{11}$

The incidence of sensitization for the next pregnancy in Rh-negative women who do not receive postpartum anti-D IgG prophylaxis is $12 \%-16 \%$, significantly higher compared to $1.6 \%$ $1.9 \%$ in women receiving postpartum prophylaxis. Anti-D prophylaxis administered within 72 hours after birth, had been shown to lower the rate of alloimmunization to $\mathrm{D}$ antigen detected at six months postpartum (RR 0.04) and during a subsequent pregnancy (RR 0.12). However, if this window is missed, there may still be some protection when anti-D is given for up to 13 days or even 28 days after a potentially sensitizing event. The Society of Obstetricians and Gynecologists of Canada (SOGC) recommends anti-D Ig 300 $\mu \mathrm{g}$ intramuscular or intravenous should be given within 72 hours after delivery. If missed, it should be given at least 28 days after delivery for nonsensitized $\mathrm{Rh}$-negative women delivering an $\mathrm{Rh}$ positive infant. ${ }^{6}$ SOGC suggests anti-D Ig $300 \mu \mathrm{g}$ administration routinely to all Rh-negative nonsensitized women at 28 weeks gestation when fetal blood type is unknown or known to be Rh-positive to avoid alloimmunization to $\mathrm{D}$ antigen. Two doses of 100-120 $\mu \mathrm{g}$ may be given at 28 weeks and 34 weeks as an alternative. All pregnant women should be typed and screened for alloantibodies with an indirect antiglobulin test at the first prenatal visit and again at 28 weeks. An additional dose of Rh immune globulin at last trimester is generally not required if the antepartum injection was given prior to 28 weeks of gestation. ${ }^{6}$ As is our case, ideally, it should be given a $300 \mu \mathrm{g}$ intramuscular or intravenous injection of anti-D immunoglobulin within 72 hours of delivery, or least up to 28 days after delivery if the initial window period missed.

\section{CONCLUSION}

This paper presents a case that illustrates the absence of clinically significant $\mathrm{RhD}$ alloimmunization due to the possibility of low immunogenicity and the dose-dependent response to fetal blood volume.

\section{PATIENT CONSENT}

Patients and families have agreed and given their consent to be reported in an academic journal.

\section{CONFLICT OF INTEREST}

The authors declared that there is no conflict of interest.

\section{AUTHOR CONTRIBUTION}

All authors have contributed equally in conducting the study, drafting and revising the manuscript, giving final approval for publication, and have agreeing to be accountable.

\section{FUNDING}

The authors report no third parties support or funding

\section{REFERENCES}

1. Chilcott J, Lloyd Jones M, Wight J, Forman K, Wray J, Beverley C, et al. A review of the clinical effectiveness and cost-effectiveness of routine anti-D prophylaxis for pregnant women who are rhesus-negative. Health Technol Assess (Rockv). 2003;7(4). Available from: http://dx.doi.org/10.3310/hta7040

2. Crowther CA, Middleton P, McBain RD. Anti-D administration in pregnancy for preventing Rhesus alloimmunisation. In: Cochrane Database of Systematic Reviews. John Wiley \& Sons, Ltd; 2013. Available from: http://dx.doi.org/10.1002/14651858. cd000020.pub2

3. Moise KJ, Argoti PS. Management and Prevention of Red Cell Alloimmunization in Pregnancy. Obstet Gynecol. 2012;120(5):1132-9. Available from: http:// dx.doi.org/10.1097/aog.0b013e31826d7dc1

4. Bowman JM, Pollack JM. Antenatal prophylaxis of rh isoimmunization: 28-weeks $\square$-gestation service program. Obstet Gynecol Surv. 1978;33(10):647-8. Available from: http://dx.doi.org/10.1097/00006254197810000-00005

5. Bowman JM, Pollock JM. Failures of Intravenous Rh Immune Globulin Prophylaxis: An Analysis of the Reasons for Such Failures. Transfus Med Rev. 1987;1(2):101-12. Available from: http://dx.doi. org/10.1016/s0887-7963(87)70010-8

6. Fung KFK, Eason E. No. 133-Prevention of Rh Alloimmunization. J Obstet Gynaecol Canada. 2018;40(1):e1-10. Available from: http://dx.doi. org/10.1016/j.jogc.2017.11.007

7. Cunningham FG, Lenevo K, Bloom S, Spong C, Dashe J, Hoffman B, et al. Williams Obstetrics. 25 th. New York: McGraw-Hill; 2018. 1328 p.

8. Tara F, Maleki A, Taheri N, Moein Darbari S. A case of $\mathrm{D}$ alloimmunization in pregnancy: successfully treated solely with therapeutic plasma exchange (TPE). J Blood Med. 2019;10:251-3. Available from: https://pubmed.ncbi.nlm.nih.gov/31440110 
9. Nassar GN, Wehbe C. Erythroblastosis Fetalis. In: StatPearls. Treasure Island (FL): StatPearls Publishing; 2019. Available from: https://www.ncbi. nlm.nih.gov/books/NBK513292/

10. Storry JR, Clausen FB, Castilho L, Chen Q, Daniels $G$, Denomme G, et al. International Society of Blood Transfusion Working Party on Red Cell Immunogenetics and Blood Group Terminology: Report of the Dubai, Copenhagen and Toronto meetings. Vox Sang. 2018/11/12. 2019;114(1):95102. Available from: https://pubmed.ncbi.nlm.nih. gov/30421425
11. Hendrickson JE, Tormey CA. Understanding red blood cell alloimmunization triggers. Hematol Am Soc Hematol Educ Progr. 2016;2016(1):446-51. Available from: https://pubmed.ncbi.nlm.nih. gov/27913514

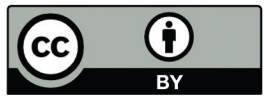

This work is licensed under a Creative Commons Attribution 